\title{
Trans-oral robotic surgery for the management of oropharyngeal carcinomas: a 9-year institutional experience
}

\author{
Chirurgia transorale robotica per il trattamento del carcinoma orofaringeo: \\ esperienza di 9 anni
}

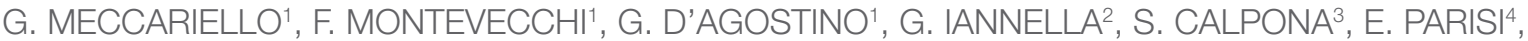 \\ M. COSTANTINI ${ }^{5}$, G. CAMMAROTO ${ }^{1,6}$, R. GOBBI ${ }^{1}$, E. FIRINU ${ }^{1}$, R. SGARZANI ${ }^{7}$, D. NESTOLA ${ }^{1}$, C. BELLINI ${ }^{1}$, \\ A. DE VITO ${ }^{1}$, E. AMADORI ${ }^{8}$, C. $\mathrm{VICINI}^{1}$ \\ ${ }^{1}$ Department of Head-Neck Surgery, Otolaryngology, Head-Neck and Oral Surgery Unit, Morgagni Pierantoni \\ Hospital, Azienda USL della Romagna, Forlì, Italy; ${ }^{2}$ Department of Organs of Sense, Ear, Nose, and Throat Section, \\ University of Rome "La Sapienza," Italy; ${ }^{3}$ Osteoncology and Rare Tumors Center, ${ }^{4}$ Radiotherapy Department, \\ Istituto Scientifico Romagnolo per lo Studio e la Cura dei Tumori (IRST), IRCCS, Meldola (FC), Italy; ${ }^{5}$ Department \\ of Surgical Pathology, Morgagni Pierantoni Hospital, Azienda USL della Romagna, Forlì, Italy; ${ }^{6}$ Department of \\ Otolaryngology, University of Messina, Italy; ${ }^{7}$ Department of Emergency, Burn Center, Bufalini Hospital, Azienda \\ USL della Romagna, Cesena, Italy; ${ }^{8}$ Radiology Department, Istituto Scientifico Romagnolo per lo Studio e la Cura \\ dei Tumori (IRST), IRCCS, Meldola (FC), Italy
}

\section{SUMMARY}

Trans-oral robotic surgery (TORS) has changed surgical management of patients with oropharyngeal squamous cell carcinomas (OPSCC). In this study we present surgical and oncologic outcomes of patients with oropharyngeal squamous cell carcinomas, treated using TORS, with and without an adjuvant therapy. Sixty patients with oropharyngeal squamous cell carcinomas treated with TORS between January 2008 and December 2017 have been retrospectively evaluated considering clinicopathologic features, disease characteristics, adjuvant treatments and oncological outcomes. TORS was performed for OPSCC to the base of tongue in 41.7\%, tonsils in 46.7\%, soft palate and posterior pharyngeal wall in $3.3 \%$ and $5 \%$, respectively. Neck dissection was performed in $43.3 \%$ of patients. Management strategies included surgery alone in 30\%, TORS and adjuvant radiotherapy in 33.3\%, and TORS plus adjuvant chemotherapy in $36.7 \%$. The 5-year overall survival of the total group was $77.6 \%$, the 5 -year disease-free survival rate was $85.2 \%$, and the 5 -year local recurrence-free survival rate was $90.6 \%$. Finally, in selected patients TORS appears to yield similar oncologic outcomes and functional outcomes to traditional techniques and non-operative treatment with a possible benefit on long-term quality of life. The future offers exciting opportunities to combine TORS and radiotherapy in unique ways. However, further research is urgently needed to clarify the indications for adjuvant therapy following TORS resections.

KEY WORDS: Robotic surgery $\bullet$ Oropharyngeal $\bullet$ Cancer $\bullet$ Neck $\bullet$ HPV $\bullet$ p16 $\bullet$ Radiotherapy $\bullet$ Chemotherapy

\section{RIASSUNTO}

Nell'ultimo decennio, la chirurgia robotica trans-orale (TORS) ha rivoluzionato la gestione chirurgica dei pazienti con carcinoma dell'orofaringe(OPSCC). Questo studio monocentrico presenta i risultati oncologici delle neoplasie orofaringee trattate con TORS con e senza terapia adiuvante nei primi nove anni della nostra esperienza robotica. Sessanta pazienti sono stati trattati tra gennaio 2008 e dicembre 2017. Sono stati acquisiti i dati riguardanti le caratteristiche clinico-patologiche, i trattamenti adiuvanti e gli esiti oncologici. La TORS è stata eseguita per OPSCC della base della lingua nel 41,7\% dei casi; nel 46,7\% per carcinoma tonsillare, mentre neoplasie del palato molle elo della parete posteriore faringea sono state rispettivamente il 3,3\% e 5\% dei casi. La svuotamento del collo è stato eseguito nel 43,3\% dei pazienti. Le strategie di gestione includevano la sola chirurgia nel 30\% dei casi, TORS e radioterapia adiuvante nel 33,3\% e TORS e radiochemioterapia adiuvante nel 36,7\%. La sopravvivenza globale a 5 anni del gruppo totale è del 77,6\%, il tasso di sopravvivenza libera da malattia a 5 anni è dell'85,2\% e il tasso di sopravvivenza libera da recidiva locale a 5 anni è del 90,6\%. Infine, in alcuni pazienti selezionati, la TORS sembra fornire esiti oncologici e funzionali simili alle tecniche tradizionali e al trattamento di preservazione d'organo con un possibile beneficio per la qualità della vita a lungo termine. Tuttavia, ulteriori ricerche sono urgentemente necessarie per chiarire le indicazioni e l'erogazione della terapia adiuvante dopo le resezioni TORS. 


\section{Introduction}

Over the past 40 years, non-operative management has become the most common therapy for oropharyngeal squamous cell carcinomas (OPSCC) due to advances in radiotherapy and the significant functional deficits left by traditional surgical approaches. On the other hand, the introduction of trans-oral robotic surgery (TORS) has led to a resurgence in the role of surgery in the management of patients with OPSCC. The oncologic efficacy of TORS is clear and for selected patients, functional outcomes are outstanding ${ }^{1}$. The goal of any oncological therapy should be to achieve long-term disease-free survival while minimising acute and late toxicities. With modern radiotherapy techniques, severe late toxicity is often minimal ${ }^{2}$. Therefore, the decision to pursue an operative versus non-operative strategy is centred on patient and tumour factors identified on history, physical exam and imaging. One of the goals of a TORS resection is to obtain negative margins on the primary tumour with minimal functional morbidity. This issue is most achieved in early OPSCC, clearly localised in an oropharyngeal subsite. Effectively, TORS was approved by the United States Food and Drug Administration for benign and malignant tumours classified as T1-2 in $2009^{3}$. Nevertheless, the use of TORS for select locoregionally advanced patients (cT3 or cN2-3) may improve oncologic control compared to chemoradiation (CRT) alone ${ }^{1}$. NCCN guidelines recognise transoral surgery as a potentially useful tool in the treatment of these selected patients ${ }^{1}$. In addition, TORS may be a valuable method of de-intensification for the locoregionallyadvanced patient in at least three ways: decreasing the dose of radiotherapy (RT); obviating the need for chemotherapy and decreasing the radiotherapy target volume.

Herein, we specifically investigate our experience in treating OPSCC patients with TORS.

\section{Materials and methods}

The medical charts of consecutive patients who underwent TORS for OPSCC at our Department between January 2008 and December 2017 were evaluated retrospectively. Clinicopathologic features of interest included age at surgery, comorbidity, sex, HPV status, final margin status, pathologic $\mathrm{T}$ classification, pathologic $\mathrm{N}$ classification, overall American Joint Committee on Cancer (AJCC) stage ( $7^{\text {th }}$ edition), extracapsular spread (ECS) and primary treatment, including TORS alone, TORS and RT, and TORS and CRT. Tumour HPV status was considered positive if either HPV in situ hybridisation or HPV p16 was positive. Exclusion criteria included distant metastases at presentation, primary treatment other than intent- to-cure, or a history of previously treated head and neck squamous cell carcinoma. The surgical approach has previously been described ${ }^{45}$. Of note, narrow band imaging (NBI) was used intraoperatively after 2010 to enhance resection of margins ${ }^{4}$. The edges of surgical excision were set at least $1 \mathrm{~cm}$ from the tumour. Negative margins or close margins were stated if more than $5 \mathrm{~mm}$ or less than $5 \mathrm{~mm}$ of surrounding free tissue was present on microscopic evaluation, respectively. Adjuvant RT was recommended for patients with $\mathrm{N} 2 \mathrm{~b} / \mathrm{N} 2 \mathrm{c} / \mathrm{N} 3$ disease, close final margins, and all patients with T3 tumours. Adjuvant CRT was recommended for patients with pathologic ECS and positive margins. Recurrence was classified as the time between surgical treatment and the date at which a patient was diagnosed with a local recurrence, nodal recurrence, or distant metastases. A second primary tumour was defined as occurring $>5$ years after initial treatment or occurring in a unique subsite separate from the original tumour bed. Additionally, a re-evaluation of tumour staging based on the $8^{\text {th }}$ edition of the AJCC cancer staging was performed. Disease-free survival (DFS), local recurrencefree survival (LRFS), regional recurrence-free survival (RRFS), total follow-up and 5-year overall survival (OS) were registered.

\section{Statistical analysis}

To test for differences among groups, Fisher's exact test was used for categorical data, while the Student's t-test was used for continuous data. The role of each possible prognostic factor (univariate analysis) and their independent effect (multivariate analysis) was explored using logistic regression model or Cox-proportional hazard model as appropriate. Survival analysis was performed by the Kaplan-Meier method. Probability values lower than 0.05 were considered statistically significant. All analyses were performed with STATA 12.1 software (Stata Corp., College Station, TX, USA).

\section{Results}

Since 2008, our institution has used TORS mainly to resect hypertrophic bases of tongue (BOT) in case of sleep apnoea disorders and surgically resectable OPSCC. Up to December 2017, 514 TORS procedure were executed. In the same period, a total of 60 OPSCC were treated with TORS alone or in combination with adjuvant RT or CRT based on pathologic cancer staging.

All patients were treated with intent-to-cure. Management strategies included surgery alone in 30\% (18/60), TORSRT in 33.3\% (20/60) and TORS-CRT in 36.7\% (22/60). Patients undergoing TORS-CRT were more likely to have 
higher nodal, ECS and overall AJCC stages $(\mathrm{p}<0.001)$. The primary tumour was classified as $\mathrm{cT} 1(22 / 60 ; 36.7 \%)$, cT2 $(23 / 60 ; 38.3 \%)$, cT3 $(6 / 60 ; 10 \%)$ and cTx $(9 / 60 ; 15 \%)$. The primary tumour arose in the BOT in 25 patients (41.7\%), tonsils in 28 patients (46.7\%), soft palate in 2 $(3.3 \%)$ and posterior pharyngeal wall in $3(5 \%)$. Unfortunately in $2 \mathrm{cTx}$, the primary was not found, while the primary was in the palatine tonsil or in the BOT in 3 and 4 cases, respectively (all pT1). Regarding HPV status, 33 (61.1\%) were considered HPV-positive.

In all patients, frozen section margins were obtained to check for clear margins. Margins remained clear in 56.7\% of patients on final pathology. Of the remaining 26 patients 4 had only positive lateral margin, while 4 had only positive deep margin. Only close lateral margin was found in 5 cases, while 6 had only close deep margin and 3 patients had close both deep and lateral margins. In all, patients with at least one positive margin were $12(20 \%)$ and those with close margins were 14 (23.3\%).

The pathological staging according the $7^{\text {th }}$ edition AJCC is shown in Table I. The re-evaluation according $8^{\text {th }}$ AJCC is displayed in Table II for HPV-/p16-OPSCC and in Table III for HPV-related OPSCC. The secondary intention healing was the predominant choice in simple and no-extensive resection's cases $(90 \% ; 54 / 60)$. One facial artery myo-mucosal (FAMM) and 1 buccinator-based myomucosal (BMM) flaps were used to cover extensive carotid exposure in two patients with a tonsillar cancer (T2). The temporalis myofascial flap (TMF) was adopted to restore a competent velopharyngeal sphincter and a watertight seal between the pharynx and neck in a case of OPSCC involving part of soft palate and the anterior tonsillar pillar (T2). In 3 cases with extensive tumour of BOT involving tonsil and soft palate (T3), the surgical defect was reconstructed with an antero-lateral thigh (ALT) free flap. Concurrent neck dissection was performed in 26 patients (43.3\%). In 15 (25\%) cases with high probability of fistula, a staged neck dissection was done after a mean of $27.7 \pm 13.4$ days (range $8-60$ ). In 7 patients $(11.7 \%$ ), the neck dissection was previously done $(-28.1 \pm 11.5$ days; range -41 to -12) because of the high risk of vascular injury or because the patient was referred to our institution for a primary tumour (unknown cases). The extent of dissection most commonly included levels IIa, IIb, III and IV. The ECS was noted in $24 \%$ of neck dissections, and the rate decreased in HPV-related OPSCC (21.4\%).

Patients undergoing TORS-RT received a mean dose of $57 \pm 5.6$ Gy on $\mathrm{T}$ (range 50-66 Gy) and a mean of $51.4 \pm 15.4$ on $\mathrm{N}$ (range $0-60$ ). In the TORS-CRT group, a mean dose of $59.7 \pm 4.2$ Gy of radiation was delivered on $\mathrm{T}$, ranging from 54 to 66 , and a mean dose of $59 \pm 3.1$ on
N (range 54-66). Further, TORS-CRT group most commonly received a mean dose of $254.5 \pm 46 \mathrm{mg} / \mathrm{m}^{2}$ cisplatin (range 180-300).

The mean duration of follow-up for the 60 patients was $30.3 \pm 26.9$ months. The 5 -year OS rate of the total group was $77.6 \%$, in case of HPV-related OPSCC the 5-year OS increased to rate of $88.2 \%$. The 5-year DFS rate was $85.2 \%(\mathrm{HPV}+$ group $=93.6 \%)$; the 5-year LRFS rate $90.6 \%(\mathrm{HPV}+$ group $=96.8 \%)$ and 5-year RRFS was $87.4 \%(\mathrm{HPV}+$ group $=93.6 \%)$.

Figure 1 shows the different survivals by HPV infection. Data for the univariate and multivariate Cox regression model are shown in Table IV. Of note, at univariate analysis positive margins were predictive of regional relapses while HPV-related cancers were related to better OS. However, the statistical significance was lost in multivariate analysis for both factors. On the contrary, at multivariate analysis, tonsillar and BOT cancers were

Table I. Clinical TNM classification $7^{\text {th }}$ ed.

\begin{tabular}{lcccccc} 
& \multicolumn{7}{c}{$\mathbf{c N}(\%)$} \\
cT & N0 & N1 & N2a & N2b & N2c & Total \\
Tx & 0 & $1(6.7)$ & $3(60)$ & $4(36.4)$ & $1(50)$ & $9(15)$ \\
T1 & $13(48.2)$ & $5(33.3)$ & $1(20)$ & $3(27,3)$ & 0 & $22(36.7)$ \\
T2 & $11(40.7)$ & $8(53.3)$ & $1(20)$ & $3(27.3)$ & 0 & $23(38.3)$ \\
T3 & $3(11.1)$ & $1(6.7)$ & 0 & $1(9.1)$ & $1(50)$ & $6(10)$ \\
Total & 27 & 15 & 5 & 11 & 2 & 60 \\
\hline
\end{tabular}

Table II. New pathological TNM classification $8^{\text {th }}$ ed. in HPV-/p16- OPSCC.

\begin{tabular}{lccccccc}
\multicolumn{7}{c}{$\mathrm{pN}(\%)$} \\
pT & N0 & N1 & N2a & N2b & N2c & N3b & Total \\
T0 & 0 & $1(20)$ & 0 & 0 & 0 & 0 & $1(4.8)$ \\
T1 & $2(33.3)$ & $1(20)$ & 1 & $1(50)$ & 0 & $1(16.7)$ & $6(29.6)$ \\
T2 & $3(50)$ & $3(60 \%)$ & 0 & $1(50 \%)$ & $1(100)$ & $3(50)$ & 11 \\
& & & & & & & $(52.4)$ \\
T3 & $1(16.7)$ & 0 & 0 & 0 & 0 & $2(33.3)$ & $3(14.3)$ \\
Total & 6 & 5 & 1 & 2 & 1 & 6 & 21 \\
\hline & & & & & & & \\
\hline
\end{tabular}

Table III. New pathological TNM classification $8^{\text {th }}$ ed. in HPV+/p16+ OPSCC.

\begin{tabular}{lcccc} 
& \multicolumn{5}{c}{$\mathbf{p N}(\%)$} & Total \\
pT & N0 & N1 & N2 & $1(3.6)$ \\
T0 & 0 & $1(6.3)$ & 0 & $13(46.4)$ \\
T1 & $4(40)$ & $8(50)$ & $1(50)$ & $11(39.3)$ \\
T2 & $4(40)$ & $6(37.5)$ & $1(50)$ & $3(10.7)$ \\
T3 & $2(20)$ & $1(6.25)$ & 0 & 28 \\
Total & 10 & 16 & 2 & \\
\hline
\end{tabular}




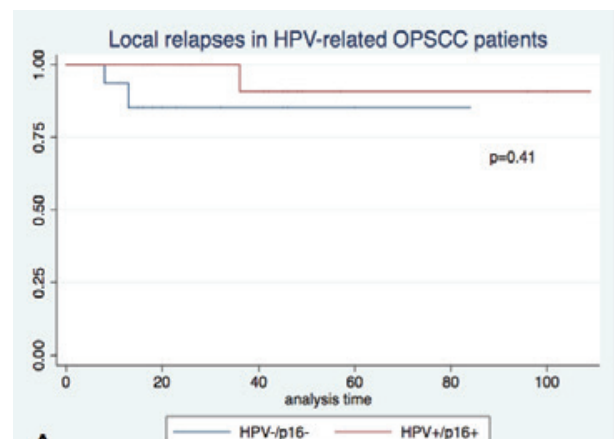

A
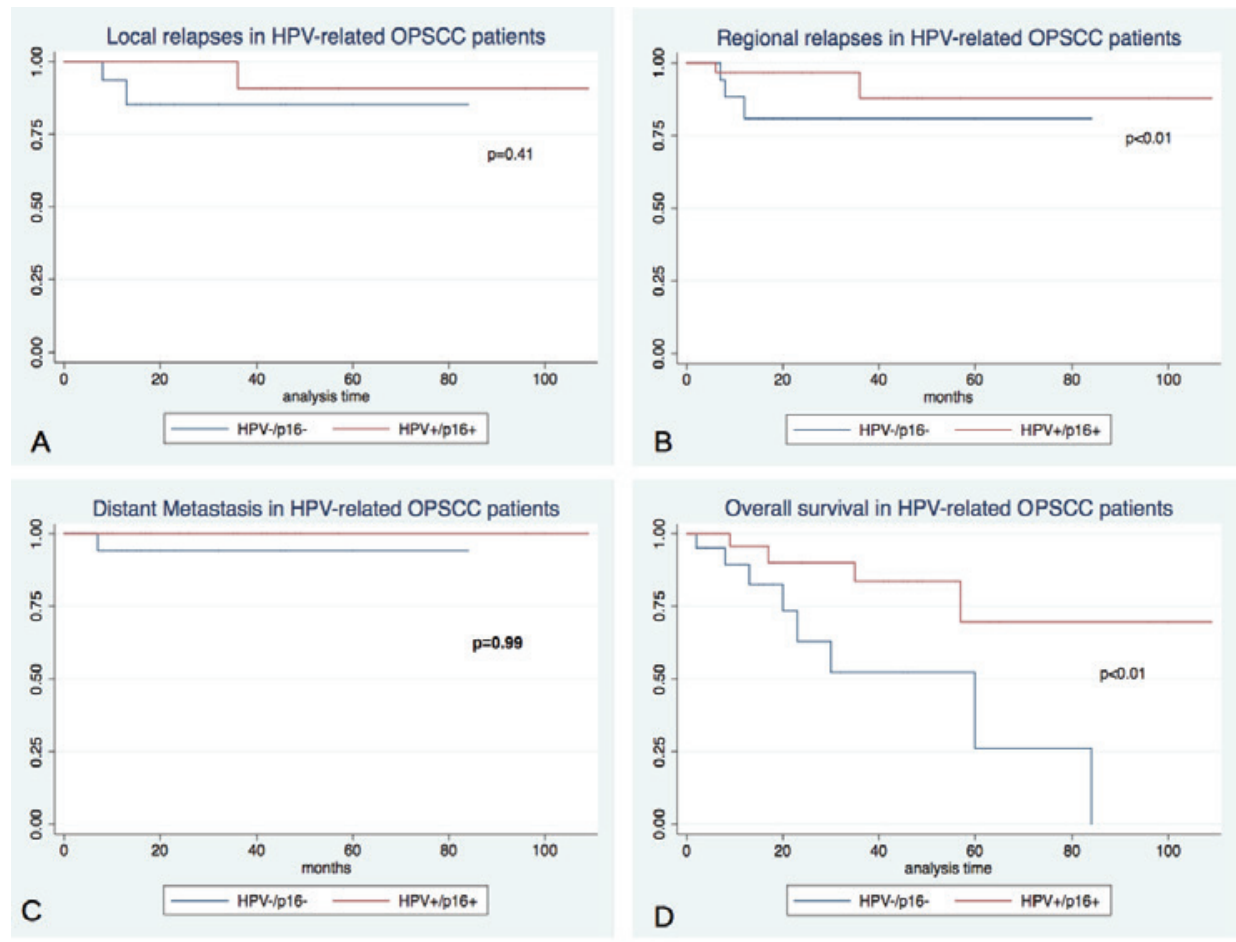

Fig. 1. A) Local Recurrence-Free Survival; B) Regional Recurrence-Free Survival; C) Distant Metastasis-Free Survival; D) Overall Survival.

significantly related with a high risk of neck recurrence, but should be considered a bias. In fact, 53 of 60 $(88.3 \%)$ patients were palatine tonsil or BOT cancers; hence, if only both sites were considered, any statistical significance not correlating the site to any risk of neck recurrence was lost $(\mathrm{HR}=6.1, \mathrm{p}=0.27,95 \% \mathrm{CI}=0.24$ 156.06).

Regarding complications, we did not register any major or life-threatening intra-operative complications. Only one patient, who had concurrent neck dissection, experienced post-operative bleeding into the neck. Eight (13.3\%) patients had post-operative bleeding from primary tumour resection field; 5 patients from tonsil and 3 from BOT. Oral bleeding had a mean of $6.2 \pm 3.7$ days. No total local or free flap failure were registered; whilst a partial necrosis of TMF that did not affect the healing and two flap dehiscences (1 FAMM and 1 ALT) that needed a surgical revision were recorded. Only the same ALT patient with flap dehiscence experienced pharyngocutaneous fistula that was treated with both surgical revision and compressive dressings. Tracheostomy was performed routinely in the first series of patients (15 cases until 2012). As our experience increased, tracheostomy was reserved only in difficult intubation cases, cT3 tumours, or cases who needed reconstruction with free flaps or local bulky flaps.
The mean duration of tracheostomy use was $7.4 \pm 2.6$ days, and nasogastric tube $14.3 \pm 6.9$ days. Only one patient (pT3N2b of BOT invading tonsil and soft palate with ALT reconstruction) experienced a post-operative severe dysphagia, needing a permanent tracheostomy tube and percutaneous endoscopic gastrostomy (PEG) feeding.

\section{Discussion}

TORS is a fascinating new tool that is useful in the modern management of selected cases of OPSCC. In a systematic review of surgical and nonoperative therapy data for oropharyngeal SCC, Yeh et al. ${ }^{6}$ found that TORS can achieve oncologic outcomes that compare favourably to primary RT, with an improved toxicity profile. In that review, TORS-based therapy OS was reported to range from $81 \%-100 \%$ and DFS from $85.7 \%-96 \%$. Recently, Moore et al. ${ }^{7}$ reported excellent outcomes with a 1, 3 and 5-year OS rate of $98 \%, 91 \%$ and $86 \%$, DFS of $99 \%, 96 \%$ and $94 \%$, and a local or regional disease-free survival rate of $95 \%, 93 \%$, and $92 \%$. Furthermore, Mahmoud et al. ${ }^{8}$ demonstrated that 3-year survival was superior in patients undergoing TORS versus non-surgically treated patients (93\% vs $83 \%, \mathrm{p}<0.001$ ), although patients with HPVpositive disease showed no significant difference in sur- 
Table IV.

\begin{tabular}{|c|c|c|c|c|c|c|}
\hline \multicolumn{7}{|c|}{ Univariate and multivariate Cox regression model for local relapses } \\
\hline & \multicolumn{3}{|c|}{ Univariate } & \multicolumn{3}{|c|}{ Multivariate } \\
\hline & HR & $P$ value & $95 \% \mathrm{Cl}$ & HR & $P$ value & $95 \% \mathrm{Cl}$ \\
\hline Age & 0.60 & 0.58 & $0.1-3.6$ & 0.75 & 0.84 & $0.5-11.22$ \\
\hline Tumour site & 0.67 & 0.53 & $0.19-2.31$ & 1.38 & 0.81 & $0.11-17.92$ \\
\hline pT & 1 & 1 & $0.3-3.25$ & 2.39 & 0.36 & $0.37-15.31$ \\
\hline pN & 1.9 & 0.2 & $0.71-5$ & 1.6 & 0.39 & $0.55-4.62$ \\
\hline Margins & 2 & 0.16 & $0.76-5.28$ & 1.96 & 0.39 & $0.42-9.19$ \\
\hline HPV & 0.25 & 0.26 & $0.02-2.81$ & 0.08 & 0.23 & $0.01-4.85$ \\
\hline \multicolumn{7}{|c|}{ Univariate and multivariate Cox regression model for regional relapses } \\
\hline & \multicolumn{3}{|c|}{ Univariate } & \multicolumn{3}{|c|}{ Multivariate } \\
\hline & HR & $P$ value & $95 \% \mathrm{Cl}$ & HR & $P$ value & $95 \% \mathrm{Cl}$ \\
\hline Age & 0.7 & 0.63 & $0.15-3.08$ & 2.17 & 0.59 & $0.13-37.42$ \\
\hline Tumour site & 1.3 & 0.5 & $0.6-2.83$ & 6.05 & 0.03 & $1.16-31.56$ \\
\hline pT & 1.54 & 0.39 & $0.57-4.17$ & 16.2 & 0.11 & $0.53-493$ \\
\hline $\mathrm{pN}$ & 1.5 & 0.34 & $0.67-3.12$ & 1.96 & 0.28 & $0.58-6.6$ \\
\hline Margins & 2.7 & 0.03 & $1.1-6.7$ & 3 & 0.27 & $0.42-21.36$ \\
\hline HPV & 0.36 & 0.27 & $0.06-2.19$ & 0.97 & 0.986 & $0.05-20.4$ \\
\hline \multicolumn{7}{|c|}{ Univariate and multivariate Cox regression model for disease-free survival } \\
\hline & \multicolumn{3}{|c|}{ Univariate } & \multicolumn{3}{|c|}{ Multivariate } \\
\hline & HR & $P$ value & $95 \% \mathrm{Cl}$ & HR & $P$ value & $95 \% \mathrm{Cl}$ \\
\hline Age & 0.92 & 0.9 & $0.23-3.66$ & 2.83 & 0.35 & $0.32-24.9$ \\
\hline Tumour site & 1.15 & 0.71 & $0.54-2.47$ & 2.93 & 0.13 & $0.73-11.85$ \\
\hline pT & 1.27 & 0.6 & 0.5-3.2 & 2.7 & 0.24 & $0.5-14.47$ \\
\hline $\mathrm{pN}$ & 1.65 & 0.17 & $0.81-3.32$ & 2.27 & 0.11 & $0.83-6.19$ \\
\hline Margins & 2.14 & 0.06 & $0.98-4.67$ & 1.59 & 0.45 & $0.48-5.27$ \\
\hline HPV & 0.27 & 0.14 & $0.05-1.51$ & 0.43 & 0.51 & $0.03-5.28$ \\
\hline \multicolumn{7}{|c|}{ Univariate and multivariate Cox regression model for overall survival } \\
\hline & \multicolumn{3}{|c|}{ Univariate } & \multicolumn{3}{|c|}{ Multivariate } \\
\hline & HR & $P$ value & $95 \% \mathrm{Cl}$ & HR & $P$ value & $95 \% \mathrm{Cl}$ \\
\hline Age & 0.99 & 0.98 & $0.34-2.86$ & 0.28 & 0.24 & $0.32-2.38$ \\
\hline Tumour site & 1.39 & 0.24 & $0.8-2.42$ & 1.92 & 0.37 & $0.47-7.9$ \\
\hline pT & 1 & 0.99 & 0.442 .28 & 1.57 & 0.68 & $0.18-13.88$ \\
\hline $\mathrm{pN}$ & 1.11 & 0.68 & $0.67-1.85$ & 0.95 & 0.94 & $0.26-3.44$ \\
\hline Margins & 1.3 & 0.33 & $0.74-2.39$ & 1.94 & 0.23 & $0.66-5.71$ \\
\hline HPV & 0.24 & 0.02 & $0.07-0.79$ & 0.23 & 0.16 & $0.03-1.81$ \\
\hline Neck Dissection & 0.8 & 0.65 & $0.3-2.14$ & 0.6 & 0.56 & $0.11-3.26$ \\
\hline ECS & 2.23 & 0.23 & $0.6-8.36$ & 8.8 & 0.22 & $0.27-292.66$ \\
\hline Radiotherapy & 0.7 & 0.56 & $0.22-2.25$ & 1.24 & 0.86 & 13.6 \\
\hline Chemotherapy & 0.21 & 0.13 & $0.03-1.6$ & 0.03 & 0.164 & $0-3.9$ \\
\hline
\end{tabular}

HR: hazard ratio; 95\% Cl: confidence interval; ECS: Extra-capsular spread.

vival by treatment modality $(\mathrm{p}=0.116)$, while the 3 yearsurvival advantage of TORS over definitive radiotherapy was only evident in the HPV-negative cohort (83\% vs $66 \%, \mathrm{p}=0.2$ ). Our data support these excellent outcomes as the 5-year DFS rate of $85.2 \%$ increased to $93.6 \%$ in case of HPV-related OPSCC, and a 5-year OS rate of $77.6 \%(\mathrm{HPV}+$ group $=88.2 \%)$.

An important consideration should be made about surgi- 
cal margins in TORS for OPSCC. No universal definition of what constitutes an inadequate resection margin exists yet ${ }^{9}$. The guidelines from the American Society of Clinical Oncology (ASCO), National Comprehensive Cancer Network (NCCN) and European Oncology Institute (IEO) all define a close margin as $5 \mathrm{~mm}$ or less without any subsite distinction. A published survey of members of the American Head and Neck Society, regarding the definition of margins, revealed that the most common cutoff for a clear margin was greater than $5 \mathrm{~mm}$ on microscopic examination ${ }^{10}$. Alicandri-Ciufelli et al. ${ }^{11}$, in their comprehensive review on surgical margins in the head and neck, reported that most studies use a margin distance of $5 \mathrm{~mm}$ or greater to define margin clearance, with the exception of glottic cancer in which there is long-standing consensus that resection margins may be as limited as 1 to $2 \mathrm{~mm}$ and still be considered adequate. For TORS resection of oropharyngeal tumours, Weinstein et al. ${ }^{12}$ defined a margin of $2 \mathrm{~mm}$ or less to be considered close and those greater than $2 \mathrm{~mm}$ considered a free margin, which has been adopted at the authors' institution. Obviously, the positive margin rate after TORS for OPSCC widely varies in the literature $(2-26 \%)^{813}$. In our study, we stated that clear margin was $>5 \mathrm{~mm}$ on microscopic evaluation, and thus we obtained $23.3 \%$ close margins and $20 \%$ positive margins.

This relative high positive margin rate, compared to outcomes at other institutions, might be affected by several factors. Our series also included all patients since the beginning of our robotic experience as well as T3 tumours that are not usually included in most published series. It is well known that the rate of clear margins increases with surgical experience; nevertheless, it is crucial to note that the experience of our pathologists in reporting clear margins increased with the workload over time. In fact, no dedicated head-neck pathologists are present in our institution. Furthermore, our hospital can be considered as a low volume centre. This issue is clearly evident in the literature. Cracchiolo et al. ${ }^{13}$ reported that the incidence of positive margins was higher in lower volume than higher volume hospitals, but improves over time.

On the other hand, other authors have failed to find surgical margin status as a significant prognostic factor in head and neck cancer ${ }^{14-17}$. Reasons for failing to find a significant impact for margin status include other variables that have a greater impact on prognosis than margins, such as limitations in standard histopathology for assessment of margin status field cancerisation and effect of postoperative RT in negating the adverse impact of positive margins. In addition, technical issues during surgery, such as tearing of the specimen, tissue retraction, or shrinkage cautery effect around tumour margins may lead to close or positive margins on the pathology report, despite complete tumour resection. However, Molony et al. ${ }^{18}$ showed that margin status had no impact on disease specific survival in patients with p16-positive disease. Similarly, Iyer et al. ${ }^{19}$ reported that margin status predicted poorer survival in p16-negative patients, but not among patients who were p16- positive. Moreover, Kaczmar et al. ${ }^{20}$ reported that margins $<2 \mathrm{~mm}$ did not lead to increased recurrence compared with margins $>2 \mathrm{~mm}$ in patients undergoing TORS. Regarding the survival, another study did not demonstrate any significant changes even after excluding TORS-treated patients with HPV-related OPSCC with positive surgical margins from 3-year survival analyses ${ }^{8}$. Usually tracheostomy is avoided in most (70-100\%) cases, regardless of the use of adjuvant therapy ${ }^{21}$, especially in early OPSCC even in case of local flap reconstruction. At many centres, tracheostomy was performed initially at the time of TORS in anticipation of airway oedema during the perioperative period; however, the majority of patients were decannulated within a few days. As the surgeons' experience increased, many of the centres moved away from routine tracheostomy at the time of TORS. In our experience, tracheostomy was routinely performed at the beginnings and then reserved to patients with difficult exposure or those with cT3 that needed regional or free flap reconstruction.

Additionally, TORS is usually associated with low morbidity rates and lower blood loss in comparison with open surgical procedures. These associated characteristics also reflect the shorter average hospital stays (4.2 days). The percutaneous endoscopic gastrostomy (PEG) dependency rate following TORS is $0-9.5 \%$ in 1 year and $0 \%$ in 2 years ${ }^{22} 23$. Another analysis of 177 patients from a multicentre study reported a long-term tracheostomy rate of $2.3 \%$, and a long-term gastrostomy tube rate of 5\%. The average duration of tracheostomy use was 7 days, and nasogastric tube 12.5 days ${ }^{23}$. Our study showed overlapping data. Amongst the TORS studies, the quality of life was investigated in only a few studies. Leonhardt et al. ${ }^{23} \mathrm{dem}$ onstrated a decline in the eating, diet and speech domains from baseline at 6 months in the postoperative course, but these scores improved to baseline levels for eating and diet by 12 months. Lee et al. ${ }^{24}$ showed improved dysphagia scores when comparing TORS to open surgery with mandibulotomy for patients with T1-T3 tonsil SCC. Dziegielewski et al. ${ }^{25}$ demonstrated a decline in all scores at 3 weeks after surgery, with the lowest scores observed at 3 months in the postoperative course. Speech attitude, aesthetic, social and overall scores eventually returned to baseline, but speech function and aesthetic scores had only partial recovery and remained below baseline scores 
at 12 months. Two studies included a comparison of quality of life (QOL) outcomes between TORS and RT. More et al. ${ }^{26}$ found that the preoperative and 3 month postoperative MD Anderson Dysphagia Index (MDADI) scores were similar between the two groups. However, by 6 months and at the 12-month postoperative follow-up, patients treated with TORS and adjuvant therapy had significantly better MDADI scores. Chen et al. ${ }^{27}$ compared QOL scales between patients who underwent initial surgical resection with either transoral laser microsurgery or TORS versus definitive CRT. At 1-year, there was no significant difference between the surgical group and the definitive chemoradiation group except for the swallowing score, which was better in the surgical group.

In one of the largest prospective studies of patients undergoing TORS ${ }^{28}$, postoperative dysphagia improved significantly more quickly in the TORS-only group vs. patients who had adjuvant CRT. In summary, the TORS-only group had significantly better scores than the TORS+CRT group in the different QOL questionnaires. Similarly, Sethia et al. ${ }^{29}$ showed that patients who underwent TORS alone had continued improvement in QOL in multiple domains shortly after surgery. These TORS-alone patients reported higher QOL scores in eating at 3 and 6 months postsurgery compared to adjuvant RT or CRT. TORS alone and adjuvant RT reported less social disruption than adjuvant CRT at 3 months, and TORS alone had higher speech scores compared to adjuvant CRT at 3 months and adjuvant RT at 6 months. Adjuvant CRT had lower overall QOL scores compared to adjuvant RT or TORS alone at baseline and 3 months, adjuvant RT at 3 weeks and TORS alone at 6 months. Although many patients in this study received PEG placement, it is important to note that the total number of patients with PEG dependence greatly diminished from 3 to 12 months. Thus, the majority of patients received PEG placement prophylactically as recommended by their radiation oncologist or as a direct result of dysphagia due to adjuvant therapy.

For what concerns surgical complications, fistula formation was noted in the series from the Mayo Clinic in 6\% of cases. These patients underwent concurrent neck dissection at the time of TORS. In all four cases, the fistulae responded to treatment with daily packing and antibiotics ${ }^{21}{ }^{30}$. Postoperative haemorrhage can be a life-threatening event in the case of TORS. The rate of postoperative haemorrhage varied $0 \%$ to $9 \%{ }^{31-35}$. Chia et al. ${ }^{36}$ summarised the common complications in a 2013 multi-institutional survey of all TORS-trained surgeons in the United States. An electronic survey was sent to 300 TORS-trained surgeons. Forty-five surgeons responded to the survey and reported a postoperative haemorrhage rate of $3.1 \%$ requiring readmission. There were a total of 6 deaths among

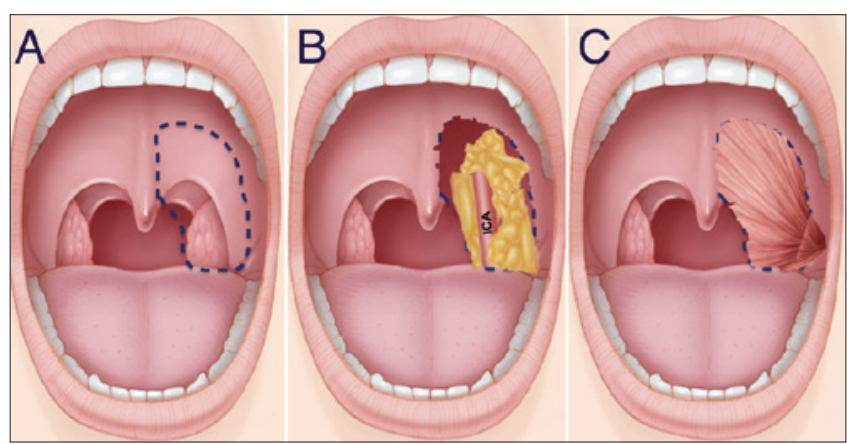

Fig. 2. Schematic illustration of the oropharyngeal resection suitable for reconstruction with the temporalis muscle flap. A) The dotted line shows the surgical resection of the area that includes part of the soft palate and the lateral pharyngeal wall; B) The surgical defect with internal carotid artery exposure; C) The temporalis muscle flap reconstruction covering the lateral pharyngeal wall and restoring the soft palate.

2015 procedures $(0.3 \%)$. Other complications included temporary hypoglossal nerve injury $(0.9 \%)$, lingual nerve injury $(0.6 \%)$ and tooth injury $(1.4 \%)$.

For what concerns reconstructive options, the majority of robotic surgeons favour leaving the oropharyngeal defects to heal by secondary intention following TORS for early OPSCC (cT1-2). However, surgical resection inevitably affects the native function of the oropharynx; therefore our group advocates the use of NBI in order to obtain free margins and reduce over-resections, consequently minimising the risk of functional impairments ${ }^{4}$. Among existing classification schemes for oropharyngeal defects, the reconstructive algorithm developed by de Almeida et al. ${ }^{37}$ seems to be easier to apply in the robotic surgery framework. In our experience, we satisfactorily used FAMM and BMM for class I/II defects ${ }^{38}$. Additionally, in a case of class III defect our group successfully adopted the TMF (Fig. 2) to restore a competent velopharyngeal sphincter and a watertight seal between the pharynx and neck ${ }^{39}$. In cases of class IV defects, we used the ALT harvested in a particular petal shape that allows one petal to replace the rear side of the palate, one for the front side of the palate and the tonsillar fossa and the third petal to reconstruct the BOT. Flap insetting is the most challenging phase due to severely restricted physical access and visualisation. However, in our experience the accurate shape and measure of the flap allow to thoroughly perform manual inset, although the robot might be used for suturing parts of flap in deeper and narrower spaces.

From an economical point of view, comparing the cost of TORS to the cost of primary radiotherapy is more challenging. In a comparative study, de Almeida et al. ${ }^{40}$ performed an extensive cost-analysis, comparing the cost of TORS versus that of primary RT for the management of early Tclassification oropharyngeal cancer. Their study accounted 
for variations in adjuvant therapy, costs, utilities, complications and recurrence rates. TORS demonstrated a cost savings of $\$ 1,366$. However, the cost-effectiveness of TORS is unlikely to be realised if used in an unselected fashion. This concept was demonstrated in three recent cost-effectiveness studies comparing TORS and radiotherapy for various populations of OPSCC ${ }^{40-42}$. The results of each study, although varied in their conclusions, demonstrate significant sensitivity to the frequency of adjuvant therapy. This implies that the use of TORS in unselected patients who are likely to require adjuvant therapy is unlikely to be a cost-effective strategy. Thus, patient selection is the key to the useful application of this modality. Furthermore, the recognition of OPSCC subgroups that would most likely benefit from TORS alone or with adjuvant treatments would be advisable in order to provide a significant treatment opportunity with fewer complications and better quality of life.

\section{Conclusions}

In selected patients TORS appears to yield similar oncologic outcomes and functional outcomes to traditional techniques and non-operative treatment with a possible benefit on long-term quality of life. Our data demonstrate comparable treatment outcomes to other published larger series. In our practice, TORS is easy and safe, and reconstruction with flaps might increase the surgical indications without compromising oncological and functional outcomes.

The future offers exciting opportunities to combine TORS and radiotherapy in unique ways. However, further research is needed to clarify the indications for and delivery of adjuvant therapy following TORS resections.

\section{Conflict of interest statement}

None declared.

\section{References}

1 Ward MC, Koyfman SA. Transoral robotic surgery: the radiation oncologist's perspective. Oral Oncol 2016;60:96-102.

2 Setton J, Lee NY, Riaz N, et al. A multi-institution pooled analysis of gastrostomy tube dependence in patients with oropharyngeal cancer treated with definitive intensity-modulated radiotherapy. Cancer 2015;121:294-301.

3 FDA 510(k) summary. 2009. www.accessdata.fda.gov/cdrh_ docs/pdf9/K090993.pdf [accessed November 18, 2015].

4 Vicini C, Montevecchi F, D'Agostino G, et al. A novel approach emphasising intra-operative superficial margin enhancement of head-neck tumours with narrow-band imaging in transoral robotic surgery. Acta Otorhinolaryngol Ital 2015;35:157-61.
5 De Vito A, Meccariello G, Vicini C. Narrow band imaging as screening test for early detection of laryngeal cancer: a prospective study. Clin Otolaryngol 2017;42:347-53.

6 Yeh DH, Tam S, Fung K, et al. Transoral robotic surgery vs. radiotherapy for management of oropharyngeal squamous cell carcinoma - a systematic review of the literature. Eur $\mathrm{J}$ Surg Oncol 2015;41:1603-14.

7 Moore EJ, Van Abel KM, Price DL, et al. Transoral robotic surgery for oropharyngeal carcinoma: surgical margins and oncologic outcomes. Head Neck 2018;40:747-55.

8 Mahmoud O, Sung K, Civantos FJ, et al. Transoral robotic surgery for oropharyngeal squamous cell carcinoma in the era of human papillomavirus. Head Neck 2018;40:710-21.

9 Sim FW, Xiao HD, Bell RB. Margin analysis: squamous cell carcinoma of the oropharynx. Oral Maxillofac Surg Clin North Am 2017;29:269-80.

10 Meier JD, Oliver DA, Varvares MA. Surgical margin determination in head and neck oncology: current clinical practice. The results of an International American Head and Neck Society Member Survey. Head Neck 2005;27:952-8.

11 Alicandri-Ciufelli M, Bonali M, Piccinini A, et al. Surgical margins in head and neck squamous cell carcinoma: what is 'close'? Eur Arch Otorhinolaryngol 2013;270:2603-9.

12 Weinstein GS, O'Malley BW Jr, Magnuson JS, et al. Transoral robotic surgery: a multicenter study to assess feasibility, safety, and surgical margins. Laryngoscope 2012;122:1701-7.

13 Cracchiolo JR, Baxi SS, Morris LG, et al. Increase in primary surgical treatment of $T 1$ and $T 2$ oropharyngeal squamous cell carcinoma and rates of adverse pathologic features: $\mathrm{Na}$ tional Cancer Data Base. Cancer 2016;122:1523-32.

14 Barry CP, Ahmed F, Rogers SN, et al. Influence of surgical margins on local recurrence in T1/T2 oral squamous cell carcinoma. Head Neck 2015;37:1176-80.

15 McMahon J, O'Brien CJ, Pathak I, et al. Influence of condition of surgical margins on local recurrence and diseasespecific survival in oral and oropharyngeal cancer. Br J Oral Maxillofac Surg 2003;41:224-31.

16 Molteni G, Valerini S, Alicandri-Ciufelli M, et al. Unravelling the risk factors that underlie oral and oropharyngeal surgery in elderly. Acta Otorhinolaryngol Ital 2018;38:409-16.

17 Cadoni G, Giraldi L, Petrelli L, et al. Prognostic factors in head and neck cancer: a 10-year retrospective analysis in a single-institution in Italy. Acta Otorhinolaryngol Ital 2017;37:458-66.

18 Molony P, Kharytaniuk N, Boyle S, et al. Impact of positive margins on outcomes of oropharyngeal squamous cell carcinoma according to p16 status. Head Neck 2017;39:1680-8.

19 Iyer NG, Dogan S, Palmer F, et al. Detailed analysis of clinicopathologic factors demonstrate distinct difference in outcome and prognostic factors between surgically treated HPV-positive and negative oropharyngeal cancer. Ann Surg Oncol 2015;22:4411-21.

20 Kaczmar JM, Tan KS, Heitjan DF, et al. HPV-related oropharyngeal cancer: risk factors for treatment failure in pa- 
tients managed with primary transoral robotic surgery. Head Neck 2016;38:59-65.

21 Moore EJ, Olsen KD, Kasperbauer JL. Transoral robotic surgery for oropharyngeal squamous cell carcinoma: a prospective study of feasibility and functional outcomes. Laryngoscope 2009;119:2156-64

22 White HN, Moore EJ, Eosental EL, et al. Transoral robotic-assisted surgery for head and neck squamous cell carcinoma: one- and 2-year survival analysis. Arch Otolaryngol Head Neck Surg 2010;136:1248-52.

23 Leonhardt FD, Quon H, Abrahao M, et al. Transoral robotic surgery for oropharyngeal carcinoma and its impact on patient-reported quality of life and function. Head Neck 2012;34:146-54.

24 Lee SY, Park YM, Byeon HK, et al. Comparison of oncologic and functional outcomes after transoral robotic lateral oropharyngectomy versus conventional surgery for $T 1$ to $T 3$ tonsillar cancer. Head Neck 2014;36:1138-45.

25 Dziegielewski PT, Teknos TN, Durmus K, et al. Transoral robotic surgery for oropharyngeal cancer. JAMA Otolaryngol Neck Surg 2013;139:1099-108.

26 More YI, Tsue TT, Girod DA, et al. Functional swallowing outcomes following transoral robotic surgery vs primary chemoradiotherapy in patients with advanced-stage oropharynx and supraglottis cancers. JAMA Otolaryngol Neck Surg 2013;139:43-8.

27 Chen AM, Daly ME, Luu Q, et al. Comparison of functional outcomes and quality of life between transoral surgery and definitive chemoradiotherapy for oropharyngeal cancer. Head Neck 2015;37:381-5.

28 Achim V, Bolognone RK, Palmer AD, et al. Long-term functional and quality-of-life outcomes after transoral robotic surgery in patients with oropharyngeal cancer. JAMA Otolaryngol Head Neck Surg 2017. doi: 10.1001/jamaoto.2017.1790. [Epub ahead of print].

29 Sethia R, Yumusakhuylu AC, Ozbay I, et al. Quality of life outcomes of transoral robotic surgery with or without adjuvant therapy for oropharyngeal cancer. Laryngoscope 2018;128:403-11.

30 Moore EJ, Olsen SM, Laborde RR, et al. Long-term functional and oncologic results of transoral robotic surgery for oropharyngeal squamous cell carcinoma. Mayo Clin Proc 2012;87:219-25.
31 Lorincz BB, Mockelmann N, Busch CJ, et al. Functional outcomes, feasibility, and safety of resection of transoral robotic surgery: single-institution series of 35 consecutive cases of transoral robotic surgery for oropharyngeal squamous cell carcinoma. Head Neck 2015;37:1618-24.

32 Lee SY, Park YM, Byeon HK, et al. Comparison of oncologic and functional outcomes after transoral robotic lateral oropharyngectomy versus conventional surgery for T1 to T3 tonsillar cancer. Head Neck 2014;36:1138-45.

33 Weinstein GS, Quon H, Newman H, et al. Transoral robotic surgery alone for oropharyngeal cancer: an analysis of local control. Arch Otolaryngol Head Neck Surg 2012;138:628-4.

34 Olsen SM, Moore EJ, Laborde RR, et al. Transoral surgery alone for human-papillomavirus-associated oropharyngeal squamous cell carcinoma. Ear Nose Throat J 2013;92:76-83.

35 Dean NR, Rosenthal EL, Carroll WR, et al. Robotic-assisted surgery for primary or recurrent oropharyngeal carcinoma. Arch Otolaryngol Head Neck Surg 2010;136:380-4.

36 Chia SH, Gross ND, Richmon JD. Surgeon experience and complications with Transoral Robotic Surgery (TORS). Otolaryngol Head Neck Surg 2013;149:885-92.

37 de Almeida JR, Park RCW, Villanueva NL, et al. Reconstructive algorithm and classification system for transoral oropharyngeal defects. Head Neck 2014;36:934-41.

38 Meccariello G, Montevecchi F, Sgarzani R, et al. The reconstructive options for oropharyngeal defects in the transoral robotic surgery framework. Oral Oncol 2017;66:108-11.

39 Meccariello G, Montevecchi F, Deganello A, et al. The temporalis muscle flap for reconstruction of soft palate and lateral oropharyngeal wall after transoral robotic surgery. Auris Nasus Larynx 2018;45:162-4.

40 de Almeida JR, Moskowitz AJ, Miles BA, et al. Cost-effectiveness of transoral robotic surgery versus (chemo)radiotherapy for early $T$ classification oropharyngeal carcinoma: a cost-utility analysis. Head Neck 2016;38:589-600.

41 Sher DJ, Fidler MJ, Tishler RB, et al. Cost-effectiveness analysis of chemoradiation therapy versus transoral robotic surgery for human papillomavirus-associated, clinical N2 oropharyngeal cancer. Int J Radiat Oncol Biol Phys 2016;94:512-22.

42 Rudmik L, An W, Livingstone D, et al. Making a case for highvolume robotic surgery centers: a cost-effectiveness analysis of transoral robotic surgery. J Surg Oncol 2015;112:155-63.

Received: May 16, 2018 - Accepted: September 15, 2018

How to cite this article: Meccariello G, Montevecchi F, D'Agostino G, et al. Trans-oral robotic surgery for the management of oropharyngeal carcinomas: a 9-year institutional experience. Acta Otorhinolaryngol Ital 2019;39:75-83. https://doi.org/10.14639/0392-100X-2199

Address for correspondence: Giuseppe Meccariello, Department of Head-Neck Surgery, Otolaryngology, Head-Neck and Oral Surgery Unit, Morgagni Pierantoni Hospital, via Carlo Forlanini 34, 47100 Forlì, Italy. Tel. +39 0543735651. Fax +39 0543735660 . E-mail: drmeccariello@gmail.com 